\title{
ONLINE REPUTATION OF CULTURAL HERITAGE ATTRACTIONS IN BULGARIA
}

DOI: http://dx.doi.org/10.18509/GBP.2020.38

UDC: $338.48-6: 930.85]: 004.738 .5: 303.6(497.2)$

\author{
Radenka Mitova \\ Elena Petkova \\ Mariana Assenova \\ Vasil Marinov \\ Geography of Tourism Department, Faculty of Geology and Geography \\ Sofia University “St. Kliment Ohridski”, Bulgaria
}

\begin{abstract}
In the context of the increasing importance of new technologies, digital marketing is an issue of utmost significance in the field of tourism and is particularly relevant in the scope of cultural tourism. Based on the information published on the Internet about selected 46 Bulgarian cultural heritage attractions, the aim of the study is to evaluate their presentation in the context of promoting and building a positive attitude towards the Bulgarian cultural heritage. The study is conducted using a specially developed methodology, simulating the presumptive online behaviour of a potential user, seeking information on the network for a specific object. The methodology seeks to gather and analyse information about the presence and distribution of content on the Internet for the sites under study, with focus on their online identity and image, resulting in and affecting the online reputation. The study revealed significant gaps and challenges with respect to the construction of online identity of cultural heritage attractions presented in detail in the paper and the serious impacts of informal electronic communication channels on their online image. Nevertheless, the online reputation of the Bulgarian cultural heritage attractions does not depend on the amount of information disseminated on the Internet and it is predominantly formed in real rather than in virtual environment.
\end{abstract}

Keywords: cultural heritage tourist attractions, online reputation, online identity, online image, online presence

\section{INTRODUCTION}

Cultural heritage is considered mainly as a resource for the development of cultural tourism products. Nevertheless, cultural tourism is more than consumption - it is a dichotomy between culture and tourism [1], where the culture should be placed in the center of the picture [2]. Institutions providing cultural tourism products have an important mission within this contradictory symbiosis - by using the cultural heritage in a commercial way, they should contribute to its promotion, meeting the specific needs of visitors, enhancing its social value and helping its conservation.

Bulgaria is a small country with a centuries-old history and rich cultural heritage. Set at important European crossroads its millennial history is marked by dramatic turnarounds that have left a deep mark on its cultural diversity. It is the country that has given the Cyrillic alphabet to the world. Thousands of cultural monuments, a variety of artifacts dating from prehistoric times to the era of totalitarism, unique testimonies from Thracian civilization, extreme ethnological and ethnographic diversity, preserved unique beliefs, 
traditions and folklore, an extraordinary amalgam of nature and authentic lifestyle are just a part of the treasury of the Bulgarian cultural heritage. Bulgaria has listed seven sites in the List of tangible culture heritage, seven items in the List of intangible culture heritage and thirteen sites in Tentative List of cultural heritage of UNESCO [3]. This is an act of recognition of the importance of Bulgarian heritage to the modern civilization. The country's cultural heritage is grounds for national pride and is a major factor in preserving national identity in the age of globalization.

Although Bulgaria has a long tradition in the development of cultural tourism, as well as a presence of significant interest in the Bulgarian cultural heritage, there is a deep sense of unfulfilled potential. Recent studies have shown that one of the main reasons hampering visits to heritage sites is the lack of information [4]. In the nowadays age of information and the rapid development of Information Communication Technology this finding raises bewilderment. A similar issue has also been raised recently in the context of factors for the rapid development of tourism in Sofia (the capital of Bulgaria) [5].

The purpose of the study is to evaluate the online presentation and analyze online offers of 46 Bulgarian heritage attractions in the context of promoting and building a positive attitude towards the Bulgarian cultural heritage. The study is organized around several hypothesis:

- The official online communication channels are not well developed and do not imply a recognizable online identity;

- Unofficial channels are a major source of online information on heritage attractions and have a significant impact on their online image;

- Linguistic differences between websites have a separation influence on the general population of users;

- The online reputation of heritage attractions depends on the amount and quality of online information disseminated.

\section{LITERATURE REVIEW}

Digital marketing in tourism, e-tourism and other related topics have been of particular interest in the scientific literature, especially in the last 20 years. This is dictated by the dramatic changes that the ever-evolving new Information Communication Technologies are causing in the tourism industry as a whole.

The Internet was recognized as a powerful cost-effective marketing tool [6;7]. It is a valuable tool for disseminating information and communication, and developing a corporate website is vital to maintaining relationships established among companies by enhancing public relations and in particular with customers. It is an important tool for communicating knowledge and information in today's society and for improving the connection between organizations and their public [8], as well as a factor for the development of economically competitive and sustainable communication strategies $[9 ; 10]$.

In a virtual environment valuable online content is also generated and shared, and thus the virtual experience can simulate real-world visits providing near-real experiences [11]. Virtual travel is very important in the decision-making process, since the tourist has a difficulty to formulate a clear image for a destination in the absence of real experience, and the multimedia interactive nature of the network can add a new dimension to the marketing of the destination [12]. Online communication enables the promotion of corporate identity - it develops its brand, builds trust and competitiveness [13], manages its online reputation and develops all its characteristics and quality. [8] 
Corporate identity is endogenous notion of an organization. On the other side corporate image expresses an exogenous view of it. Image and identity are elements of the organization's reputation, which is a broader construct. It reflects the cumulative image of the organization of internal and external stakeholders. The discrepancy between image and identity can have a negative impact on reputation. If we assume that image and identity interact like docked vessels, we should change identity to change the image [14]. Corporate identity is the way in which corporate entities (actors who perceive themselves as acting on behalf of the organization) interpret their organization in the context of an ongoing social interaction with other entities [15].

Online reputation is corporate reputation created in an online environment [16]. It is formed by all the content that an organization distributes about itself, as well as information that is distributed in the virtual space by other entities (suppliers, users, competitors, partners, etc.), reflecting how others view the organization when they search for it online [17]. Thus, electronic reputation depends on two types of communication channels:

- Official channels - websites and social networking profiles related to and managed by the organization and

- Unofficial channels over which the organization has no control - other sites, search engines, social networks, etc. [18; 19; 20]

Official website and / or social media page, by providing official information about the organization over which it has complete control, can be interpreted as an expression of its online identity, which in turn builds its image in the virtual space.

\section{METHODOLOGY}

\section{Sample}

The study is focused on 46 sites in Bulgaria defined as cultural heritage attractions. They are located in four areas: Koprivshtitsa-Hisarya-Kazanlak, Veliko Turnovo-GabrovoTryavna, Ruse and its adjacent sites and Pleven-Lovech. The selection of sites is based on the following set of criteria: diversity by type (historical period, scientific and cultural field), form, environment, utilization, popularity and belonging to different tourist regions according to the Concept for Tourist Regionalization of Bulgaria [21]. The attractions were explored on-site through interviews with site operators and visitor surveys. Some results of the 668 surveys with visitors to 30 sites were used in this analysis.

\section{Gathering and analyzing information}

A specific subject of this study is the information published online for each of the attractions studied, focusing on their online reputation. We want to explore the relationships built in the virtual space between the operators of the studied heritage attractions, in their capacity as providers of tourism services, and potential consumers, i.e. in its marketing aspect. The study aims to gather and analyze information about the presence and distribution of content for a heritage attraction on the Internet, mimicking the alleged online behavior of a potential user seeking information on the network for each specific site included in the survey.

First, information was sought on the availability of one's own sites and pages in one or more social networks with a view to building one's online identity. The presence or absence of any particular attraction on a site of a higher organizational structure (cultural 
institution and / or municipality), as well as the maintenance of unofficial websites for the site managed by third organizations or persons, are also taken into account.

The second stage focuses only on those sites that were found in the first stage of the survey to maintain their own official site. For the purposes of the analysis, a benchmarking matrix has been developed based on coding the content of the websites, taking into account the presence or absence of information about a given service supply element. The matrix has been prepared by an overview of the official websites of the world's leading cultural heritage attractions such as Stonehenge (UK) [22], Louvre (France) [23], Acropolis (Greece) [24] and Leonardo da Vinci Museum (Italy) [25]. This approach was chosen to ensure comparability with the practices in Bulgaria of presenting and promoting the Bulgarian cultural heritage, as well as with the degree of development of the product of heritage tourism with the global trends. The review of these sites revealed significant similarities in the information provided in the online environment for the services offered, targeting potential visitors in five main thematic dimensions: accessibility (visit planning), basic information services, events, amenities and entertainments.

Quantitative information on the total number of results was collected by Google keyword searching for each site in Bulgarian and English. Based on this information, conclusions can be drawn about the extent of information dissemination for an object that is accessible to users in the virtual space, as well as the degree of virtual popularity of the object for both Bulgarians and foreigners.

The information presence for each attraction was investigated in selected groups of websites:

- The most popular worldwide websites of general type - Wikipedia (in Bulgarian and English), Google Maps, You Tube (in Bulgarian and English);

- Popular international travel websites - TripAdvisor and Lonely Planet;

- National tourist websites - bulgariatravel.org, btsbg.org - 100 National tourist sites, Opoznai.bg and iloveBulgaria;

- Tags from users on popular social networks - Facebook, Twitter and Instagram.

Also reflected are user-generated ratings for sites and the number of registered comments on Google Maps, TripAdvisor and Opoznai.bg. Thus, the survey included those unofficial sources of information that are supposed to play a key role in building the online reputation of the sites over which their operators have no control and which have a significant influence on the choice and decision making of visits in the minds of Bulgarian and foreign consumers.

The information collected was processed using statistical analysis techniques.

\section{RESULTS AND DISCUTION}

\section{Official channels for online communication}

All the attractions explored are presented in the virtual space and have their online identity in a different kind of format. The analysis of the official channels for online communication shows that only 16 of the 46 surveyed heritage attractions (34.8\%) have their own official website. These sites in the dominant part of the cases are the governing cultural institutions (regional, historical or archeological museum, gallery, etc.). The exceptions to this rule are only 9\%. In contrast, almost all sites (95.7\%) have pages on one or more social networks - most often on Facebook. Simultaneously, $85 \%$ of the sites studied are presented on the websites of a higher-level cultural institution - the one under 
which jurisdiction the respective attraction is assigned. Affiliates of the governing cultural institutions are included in this group of attractions. The share of attractions that are presented on the websites of the municipalities on the territory of which the respective site is located is high - $87 \%$. Four sites $(9 \%)$ do not have their own site or are not represented in a website of a higher-level cultural institution, and the attractions ignored by the municipal websites are $13 \%$. The share of sites presented on unofficial websites maintained by third parties or organizations is extremely high $-95.7 \%$.

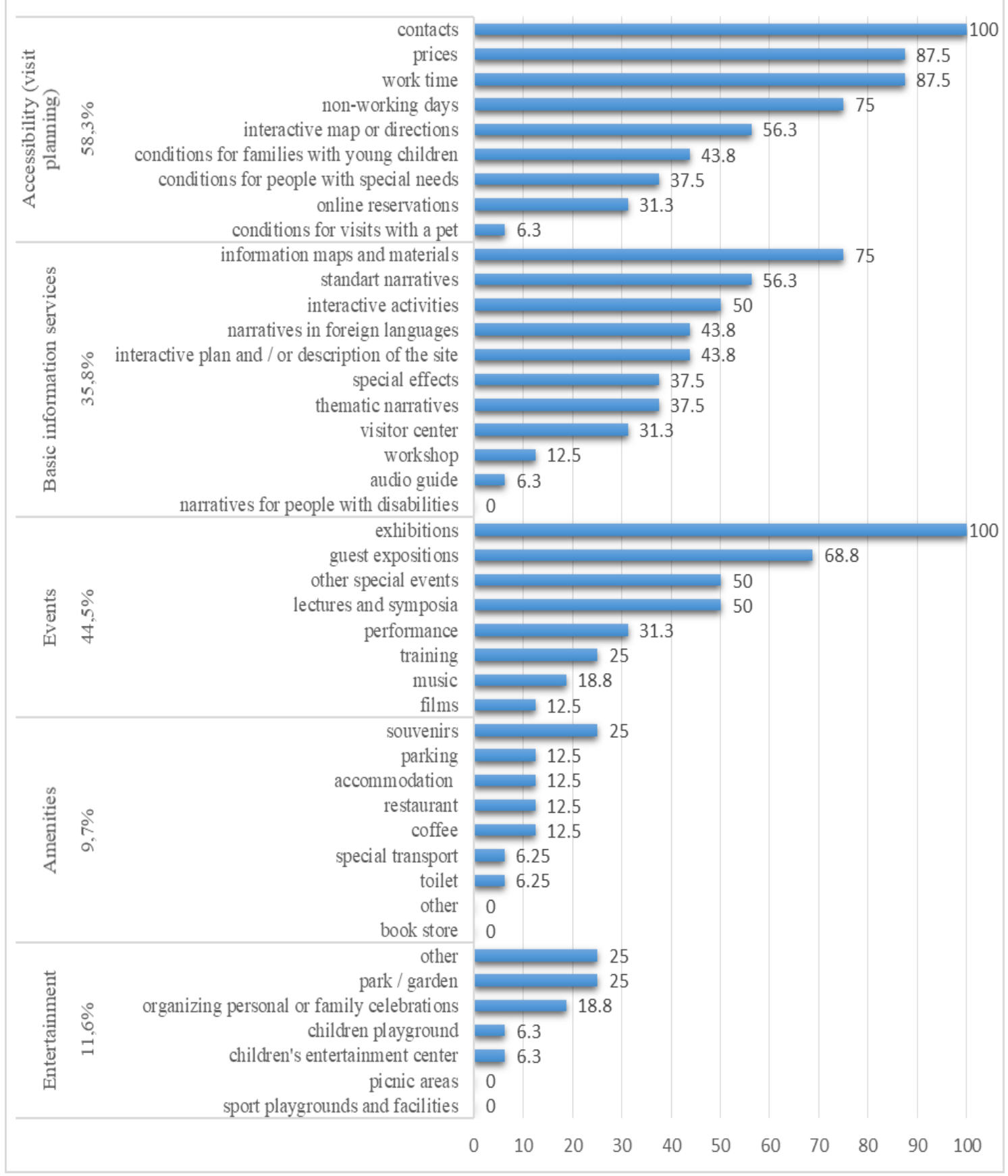

Figure 1. Degree of presentation of supply elements

The process of building an online identity seems to be largely subordinated to the governance structure of Bulgarian heritage attractions, with leading role of cultural institutions and municipal administrations. The share of heritage attractions that have 
limited control over the process of building their online image on the basis of their own online identity based on their own website is very high $-65.2 \%$. It seems paradoxical that even the sites included in the UNESCO List of World Heritage listed in the study - the Kazanlak Tomb and the Ivanovo Rock Churches do not have their own websites. They are featured on the websites of the cultural institutions in charge.

From the perspective of a potential online user seeking official information about a particular heritage attraction, this approach to presenting sites and building their online identity seems inadequate. The approach is institutional rather than object-oriented, which makes it difficult to seek information about specific heritage attractions.

This conclusion is supported by the results obtained from a field survey of visitors regarding their informational behavior. Although $90 \%$ of the surveyed visitors stated that they were informed in advance of the sites visited, and $38 \%$ of them used the Internet as a source of information, only $3.1 \%$ were informed from the official websites of the attractions, and only $1.4 \%$ - from local (municipal) websites. In the structure of online sources only, the share of official attraction websites remains low $-7.5 \%$ and the share of local sites - only $3.3 \%$.

The analysis of the content of the 16 official websites of Bulgarian heritage attractions with a focus on specific tourist information is indicative of the quality of presentation of their online offer addressed to the potential costumer. Compared to selected world cultural attractions, the presentation of supply elements shows an overall unsatisfactory level $32.8 \%$

Fig. 1 presents in detail the results of the benchmark analysis of attractions' official websites. The data shows serious gaps in the presentation of all major supply elements, but they appear to be very sharp in the secondary supply area, and in particular - in the area of amenities and entertainment. The survey also registered serious shortcomings in the presentation of the elements of the primary supply, mainly with respect to basic information services, but there were also significant gaps in the accessibility of the attractions.

Although further studies are needed, the findings provide a significant answer to the question of why visitors to Bulgarian cultural heritage attractions resort to other sources and do not use official attraction websites as a major online information channel. The information published on the official websites of cultural heritage attractions does not substantially meet the needs of potential visitors for specific tourist information and it is not sufficiently costumer-oriented.

\section{Informal channels for online communication}

If the potential customers do not rely on attractions' official websites, they probably seek information from other sources. The results of a survey among visitors to heritage attractions show that the Internet is not among the top but it is essential as a source of information for $37.7 \%$ of respondents. Of greater importance are the traditional informal $(45.8 \%)$ and formal $(45.3 \%)$ channels. These results raise the question: is the available information about attractions on Internet sufficient?

On the other hand, the main sources of online information about the attractions mentioned by the visitors are specialized tourist portals especially those with increased international weights - TripAdvisor and Lonely Planet (20.4\%), followed by national web travel guides $(18.8 \%)$. Wikipedia (17.5\%) has the highest share of general type of websites, which is comparable to the specialized tourist websites. Social networks - Facebook, Instagram and Twitter - have a $15 \%$ share, followed by Google Maps with 7.5\%. Mobile apps 
(iloveBulgaria - $1.7 \%$ ) and popular video sharing website You Tube $(0.8 \%)$ are of least importance. The results indicate that the visitors are searching for specific tourist information, but are they able to find it?

The survey shows that the available online information about attractions seems sufficient. The total number of results for all the heritage attractions explored by keyword search on Google is 7943 478, of which 4516240 are search results in Bulgarian and 3427238 in English. The average number of search results in Bulgarian is 98179 and in English - 74 505. The total number of videos distributed for the studied heritage attractions is 232818 , of which 164755 are in Bulgarian and 68063 in English. The average number of videos in Bulgarian is 3582 and in English - 1480. The number of news broadcasts about the studied attractions is 279 763, including 229720 in Bulgarian and 50043 in English.

However, the studied sites are distinguished by varying degrees of virtual popularity. More than $82 \%$ of the attractions are characterized by a low degree of dissemination of information in Bulgarian and the remaining $18 \%$ by a high and very high degree. In English content distribution the share of low-popular sites is lower (63\%), at the expense of high-value (26\%) and very high-value (11\%) attractions.

In the specialized world travel websites TripAdvisor and Lonely Planet, in which the information is published only in a foreign language, the performance of the explored attractions is at a relatively good level, with $85 \%$ and $67.4 \%$ presence of the websites respectively. More than half ( 26 items or $56.2 \%$ ) of the sites are presented simultaneously on both websites, and 18 items $(39.1 \%)$ are represented either on one website or on the other.

Contrary to the above, the level of presentation of the studied sites in Bulgarian tourist portals maintained by public or related structures (Ministry of Tourism and Bulgarian Tourist Union) is lower than that of the world tourist websites. The number of sites included in the bulgariatravel.bg portal in which the content is published in 10 languages is $24(52.2 \%)$, and those listed on the btsbg.org website - 100 National tourist sites in Bulgarian are only $22(47.8 \%)$. In contrast, the presentation of the attractions in the private online travel guides of Opoznai.bg (in Bulgarian only) and iLoveBulgaria (in Bulgarian and English) is at a very high level, with $97.8 \%$ and $100 \%$ respectively.

The results of a staged virtual trip to the world's most visited websites show that the studied heritage attractions are most fully represented on Google Maps - 97.8\%. A similar, very high percentage of site presence is registered on the video sharing site You Tube, but only when searching in Bulgarian - 95.7\%. However, when searching for English content on You Tube, the share of featured sites is below 3/4, with any information being found on the 12 attractions. Similar is the picture when searching in Bulgarian on Wikipedia - $76.1 \%$ of the sites have published information, but when searching in English the proportion of the featured sites falls below 50\%, with no content found for 25 attractions.

The dissemination of information about explored attractions in the form of tags on the popular social networks Facebook, Twitter and Instagram shows different weight. The highest activity is logged on Facebook, where content appears for 42 attractions or $91.3 \%$. About $60 \%$ of the sites' presence is also noted on the Instagram network. The least is the presentation of attractions on the Twitter network, in which information appears only for 19 sites, which represent only about $40 \%$ of the studied attractions. For four attractions there are no user reviews at all on any social network.

In conclusion, there is a lot of information published on Internet but dissemination of content about Bulgarian heritage attractions is uneven by sites, by type of information, 
and by language. Furthermore, there are serious gaps in terms of specific tourist content, both by attractions and by language of publication and searching for such information, seems to be too complicated.

\section{User-generated online rating}

It is well known that the content of most unofficial websites mentioned above is generated by the users. It is curious to find out what are their attitudes towards the Bulgarian heritage attractions. Table. 1 presents some indicators of a statistically variation analysis of the user-generated ratings of the studied heritage attractions at the Opoznai.bg, TripAdvisor, and Google Maps, where the user rating systems have been established.

Table 1. Statistical variation analysis of user-generated online ratings

\begin{tabular}{llll}
\hline indicators & Opoznai.bg & TripAdvisor & Google maps \\
\hline number of included sites & 45 & 39 & 44 \\
\hline share of included sites $(\%)$ & 97.8 & 84.8 & 95.7 \\
\hline number of rated sites & 45 & 38 & 43 \\
\hline share of rated sites $(\%)$ & 97.8 & 82.6 & 93.5 \\
\hline average number of site evaluations & 50.1 & 72.3 & 744.3 \\
\hline minimum number of site evaluations & 1 & 1 & 5 \\
\hline maximum number of site evaluations & 1429 & 1214 & 6866 \\
\hline standard deviation of the number of evaluations & 210.3 & 179.2 & 1376.2 \\
\hline the median of number of evaluations & 7 & 32 & 276.5 \\
\hline range of the number of evaluations & 1428 & 1213 & 6861 \\
\hline average score & 4.67 & 3.58 & 4.43 \\
\hline minimum score & 4 & 3.5 & 4 \\
\hline maximum score & 5 & 5 & 4.9 \\
\hline standard deviation of scores & 0.77 & 1.69 & 0.97 \\
\hline the median of scores & 4.9 & 4.5 & 4.7 \\
\hline range of the scores & 1 & 1.5 & 0.9 \\
\hline dispersion of scores & 0.6 & 2.8 & 0.9 \\
\hline coefficient of variation $(\%)$ & 16.5 & 47.1 & 22.0 \\
\hline & control value & 0.89 & 0.28 \\
\cline { 2 - 4 } effect size (Cohen's d) & 0.28 & 0.32 & control value \\
\cline { 2 - 4 } & 0.87 & control value & 0.64 \\
\hline
\end{tabular}

The results show that at all three websites the level of presentation of the studied attractions is high, but in TripAdvisor it is slightly lower $-84.8 \%$. The level of evaluated sites also shows high values - over $85 \%$. The average number of rates varies widely. It is the highest on Google maps, while the average rating on Opoznai.bg and TripAdvisor is significantly lower. The data shows that some objects are much more highly rated than others are. In all cases, the generated user ratings are highly dependent on the extreme values of the number of ratings due to the uneven distribution of the number of evaluations.

The average user rating of the studied heritage attractions shows different values but, in any case, they fall within the range of positive evaluations. Absolute maximum ratings are typical of TripAdvisor and Opoznai.bg, while Google Maps has the highest user rating of 4.9. The most critical are the users of the TripAdvisor, which has the lowest ratings of 3.5. In the other websites, the minimum ratings are 4. However, the minimum rating of all three sites is in the range of positive ratings. The dispersion values of the mean ratings - standard deviation, variance, and coefficient of variation show the highest values for TripAdvisor ratings, followed by those on Google Maps, and at Opoznai.bg they show the highest concentration. The different approaches in rating averaging are likely to have 
an effect on variance, as evidenced by the high variation coefficient on TripAdvisor data. The median values of the average scores at all three websites show a strong asymmetry in favor of the positive ratings, but they are the lowest on TripAdvisor -4.5 and the highest on Opoznai.bg - 4.9 and those on Google Maps occupy an intermediate position - 4,7.

In order to test the hypothesis for sample differences at the three websites the effect size factor (Cohen's d) was calculated - Table. 3. The results confirm the hypothesis that linguistic differences between websites have a decisive influence on the general population, especially in the case of TripAdvisor (in English only) and Opoznai.bg (in Bulgarian only).

Fig. 2 graphically depicts the frequency distributions in percent of the ratings generated by the users. In order to ensure better comparability between the data due to the differences in the averaging of the assessments, a comparison was made over the evaluation ranges as follows: 1) No rating; 2) 3.5-4 - the lowest rates, 3) 4.1-4.5 - the high rates and 4) 4.6-5 - the highest rates.

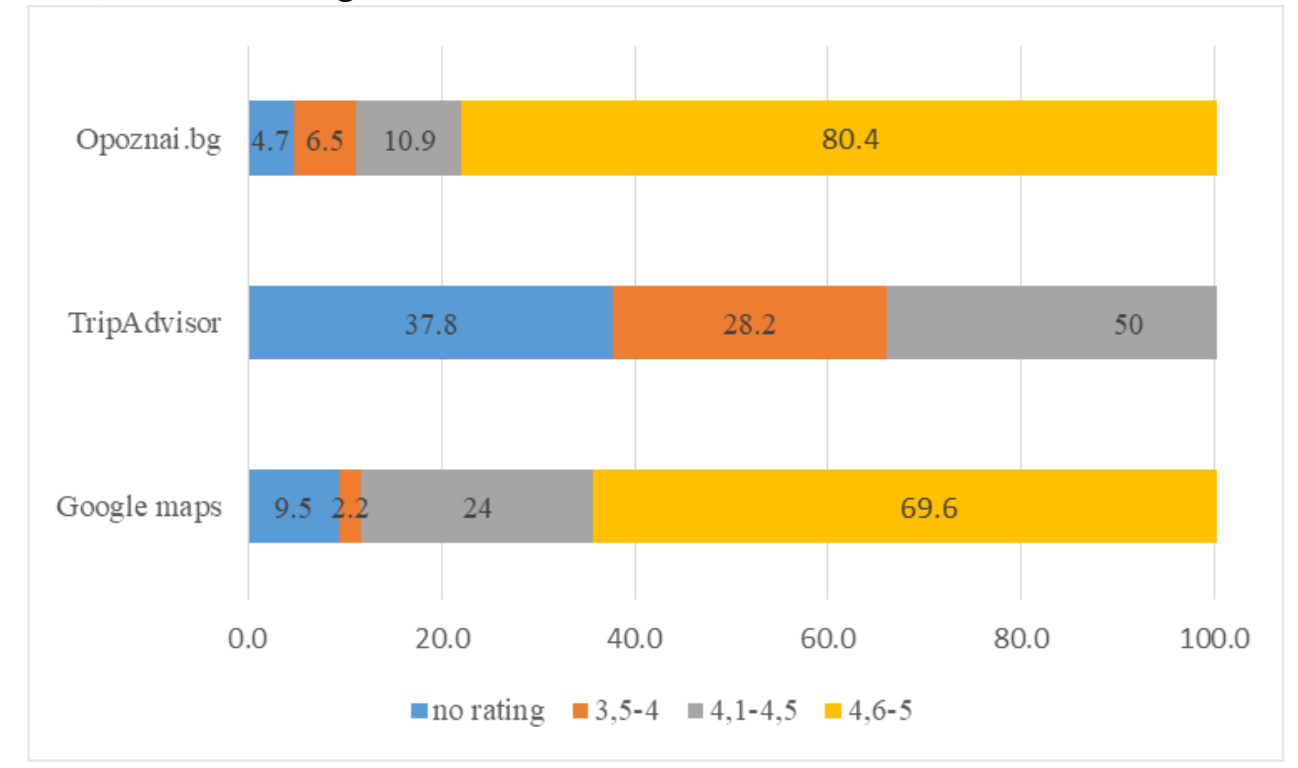

Figure. 2. Frequency of user-generated ratings for heritage attractions in selected websites, $\%$

The chart shows that TripAdvisor users are reluctant to give the highest rates - the share of the highest ratings range is negligible. In addition, they are much more critical than the users of the other two websites - the frequency of the range of lowest ratings is significantly higher than that of the other websites (28.2\%). TripAdvisor users most commonly cited ratings in the medium to high range, which can be interpreted as overall satisfactory rating. Compared to the other two websites, the proportion of unrated sites is also very high.

The picture on Opoznai.bg looks completely different. More than $80 \%$ of the ratings fall in the range of the highest marks and about $11 \%$ are in the range of the average grades. This means that the overall rating of the website's users comes close to being excellent. Although much less pronounced than TripAdvisor, there is also some user criticism - the lowest ratings are $6.5 \%$. Obviously, users of Opoznai.bg appreciate highly researched heritage attractions and tend to neglect the disadvantages. The share of unrated sites is the lowest compared to the other two websites.

The picture on Google Maps seems to be a consensus between those of the other two websites, but it seems to be closer to the situation on Opoznai.bg. The share of the highest rated range $(69.6 \%)$ is significantly higher than the other ranges, but it is smaller than the 
one in the Opoznai.bg. The share of the range with medium scores $(24 \%)$ is also significant, but the share of the range with the lowest grades is only $2.2 \%$. Obviously, Google Maps users demonstrate moderately high satisfaction with the attractions explored.

\section{Impacts of online presentation on online ratings}

A regression analysis was performed to check the impact of the extent and quality of the online presentation of the heritage attractions on the consumer ratings. First, a correlation was searched between the number of reported Google search results (in Bulgarian and in English) and user ratings on the Opoznai.bg, TripAdvisor, and Google Map websites for all attractions. In the same way, the relationship between the degree of presentation of the supply elements and the consumer rating was examined for those attractions, which maintain one's official website. (Table 2)

Table 2. Correlations between online presentation and online ratings

\begin{tabular}{lllllll}
\hline & \multicolumn{2}{l}{$\begin{array}{l}\text { Rating } \\
\text { Google maps }\end{array}$} & \multicolumn{2}{l}{$\begin{array}{l}\text { Rating } \\
\text { TripAdvisor }\end{array}$} & \multicolumn{2}{l}{$\begin{array}{l}\text { Rating } \\
\text { Opoznai.bg }\end{array}$} \\
\cline { 2 - 7 } Number of Google results & BG & EN & BG & EN & BG & EN \\
\hline Coefficient of correlation $(r)$ & 0,5 & 0,4 & 0,4 & 0,1 & 0 & 0,1 \\
\hline Coefficient of determination $\left(r^{2}\right)$ & 0,3 & 0,2 & 0,2 & 0,01 & 0 & 0 \\
\hline $\begin{array}{l}\text { Degree of presentation of } \\
\text { supply elements }\end{array}$ & & & & & & \\
\hline Coefficient of correlation $(r)$ & $-0,32$ & & $-0,11$ & & 0,37 & \\
\hline Coefficient of determination $\left(r^{2}\right)$ & 0,1 & & 0,01 & & 0,14 & \\
\hline
\end{tabular}

Correlation coefficient values $(r)$ in the relationship between the virtual popularity of sites and their online rating range from average to completely missing dependency. The values of the coefficient of determination $\left(r^{2}\right)$ indicate that in cases where such a relationship is manifested, it is not linear and has a less pronounced functional character. This dependency is wholly absent or poorly expressed in ratings on specialized travel websites, but in case of Google Maps rating, it shows higher statistical significance.

The interpretation of the above results indicates that the amount of information published in the virtual space has too little or no influence on the online reputation of Bulgarian heritage attractions. The online image of Bulgarian heritage attractions depends more on other factors than on the volume of published information.

This gives a reason to suppose that probably it does matter what is the character and purpose of the published content, to whom it is addressed, where it was published and who published it. This may means that building a positive online image of Bulgarian heritage attractions requires focused actions and efforts aimed at disseminating information with specific content and a clear message, in the right place, with a clear sender and receivers.

However, the correlation coefficient $(r)$ between the degree of presentation of the supply elements on the official websites of the attractions and their online rating completely refutes this assumption. It shows that such dependence is not simply missing, but even reversed. The coefficient of determination $\left(r^{2}\right)$ in this connection shows that the manifestation of the dependence between the two determinants is completely random.

An explanation may be that a higher level of accessibility to and quality of online information is likely to be important in the planning and decision-making stages of the visitation, but the rating of attractions on tourist websites is actually generated after the realization of the visit and getting real impressions. This may mean that even the online 
reputation of Bulgarian heritage attractions is formed more in real than in virtual environments.

\section{CONCLUSIONS}

Aiming to evaluate the performance and analyze the online offerings of 46 Bulgarian heritage sites, the survey revealed significant gaps and challenges in building online identity in the form of websites.

The approach in the process of building online identity is not object oriented, but highly centralized, which on the one hand restricts the independence and control in the process of building the online identity of attractions, and on the other, makes it difficult to find the necessary information from a user point of view. In addition, compared to the global trends, the online offer of attractions has been developed to an unsatisfactory level. Serious gaps are recorded in all major supply elements, but they are very acute in the secondary supply area, and in particular in the area of amenities and entertainment. Poorly targeted at potential users, the information published on official sites does not meet their specific tourist information needs.

The gaps of official communication channels divert user demand to unofficial online channels, which are the main source of online information about Bulgarian heritage attractions and a major factor in building their online image. However, the distribution of unofficial online information is uneven in terms of attractions, type of information and language. Furthermore, there are serious gaps in terms of specific tourist content, both by attractions and by the language of publication. Searching for such information seems to be too complicated.

However, all Bulgarian heritage attractions have a positive image according to online user rating systems. Nevertheless, the results of the analysis lead to the conclusion that the image among foreign users is less favorable than among Bulgarian users.

The assumption, that the more information is disseminated in the virtual space for a given heritage attraction the greater the impact on its image, is rejected by the results of the analysis. This means that the information dissemination of whatever, wherever and by whoever has no significant impact on the online reputation of Bulgarian heritage attractions. Undoubtedly, overcoming the gaps and challenges of official online communication channels is essential, especially in regards of pre-briefing potential customers.

The hypothesis that the better presentation of the elements of supply on the official websites leads to better effect on their image is completely rejected. The results of the analysis lead to the conclusion that the virtual presentation of the attractions cannot replace the real experience and online reputation of Bulgarian heritage attractions is actually formed predominantly in the real rather than in the virtual environment.

The applied methodological "put on user's shoes" approach, combined with the concept of corporate reputation, allowed for a clearer picture regarding the digital presentation of some of the Bulgarian heritage attractions. The results are applicable for making recommendations to the governing institutions in order to improve the promotion of the Bulgarian cultural heritage and to create a positive attitude towards it. The developed methodological framework allows extensions in the direction of the range of attractions, analysis of more qualitative aspects and analysis of the marketing strategies of the sites. 


\section{Acknowledgement}

The research was supported by the Bulgarian Ministry of Education and Science under Cultural Heritage, National Memory and Society Development National Research Program, approved by DCM No 577/17 August 2018.

\section{REFERENCES}

[1] Richards, G. The Development of Cultural Tourism in Europe. In: Cultural Attractions and European Tourism. (Ed. G. Richards), CABI, 2001, 269 p.

[2] Richards, G. What is Cultural Tourism? In: Erfgoed voor Toerisme, Weesp: Nationaal Contact Monumenten. (Ed. A.van Maaren) 2003.

[3] https://whc.unesco.org/

[4] Cultural Tourism - Product Analysis, Explica - Global Metrix DZZD, 2019 (Bg)

[5] Dogramadjieva, E., R. Mitova \& V. Nikolova. Qualitative study of local tourism development based on interviews with key informants: the case of Sofia city, Annual of Sofia university "St. Kliment Ohridski”, Book 2 - Geography, Vol. 111, 2018, p. 191(Bg)

[6] Buhalis, D. E-tourism: Information technology for strategic tourism management. Harlow, UK: Prentice Hall. 2003.

[7] Buhalis, D. \& Law, R. Progress in information technology and tourism management. 20 years and 10 years after the Internet. The state of etourism research. Tourism Management, 29 (4), 2008, pp. 609-623.

[8] Pitana, I. \&P. Pitanatri. Digital Marketing in Tourism: The More Global, The More Personal, International Tourism Conference: Promoting Cultural and Heritage Tourism, Bali, 2016, retrieved from

https://www.academia.edu/40634941/DIGITAL_MARKETING_IN_TOURISM_The_More_Gl obal_The_More_Personal

[9] Chaudhri, V. \& J.Wang. Communicating Corporate Social Responsibility on the Internet. Management Communication Quarterly, 21(2), 2007, pp. 232-248.

[10] Mcmahan, C., Hovland, R. \& S. Mcmillan. Online Marketing Communication: Exploring online Consumer Behavior by examining gender differences and interactivity within internet advertising. Journal of Interactive Advertising. 10(1), 2009, pp. 61-76.

[11] Buhalis, D., Leung, D. \& R. Rob Law. eTourism: Critical information and communication technologies for tourism destinations. Destination Marketing and Management, 2011, pp. 205224.

[12] Hadžić, O. Tourism and digitization of cultural heritage. Pregled nacionalnog centra za digitalizaciju, vol. 5, 2004, pp. 74-79.

[13] Buhalis, D., \& R. Wagner. E-destinations: Global best practice in tourism technologies and applications. In: Information and Communication Technologies in Tourism (Ed. L. Cantoni, \& Z. Xiang).Vienna, Austria: Springer Verlag, 2013, pp. 119-130

[14] Chun, R. Corporate Reputation: Meaning and Measurement. International Journal of Management Reviews, vol. 7 (2), 2005, pp. 91-109

[15] Prevelli, P. Chinese Corporate Identity. Routledge, 2006

[16] Jones, B., Temperley, J. \& A. Lima. Corporate reputation in the era of Web 2.0: The case of Primark. Journal of Marketing Management, 25 (9), 2009, pp. 927-939.

[17] https://www.reputation.com/

[18] Weber, L. Marketing to the social web: how digital customer communities build your business. Hoboken: John Wiley \& Sons, 2007. 
[19] Rice, D. Managing your reputation in a virtual world. Security Distributing \& Marketing, vol. 40 (3), 2010, pp. 93-100.

[20] Vartiak, L. Benefits of online reputation management for organizations operating in various industries. TRANSCOM 2015, 22-24 June 201

[21] Concept for Tourism Regionalization of Bulgaria (2014). National Center for Territorial Development Ltd., Ministry of Economy and Energy, Sofia, (Bg)

[22] https://www.english-heritage.org.uk/visit/places/stonehenge/

[23] https://www.louvre

[24] https://www.theacropolismuseum.

[25] https://www.mostredileonardo.com 